\title{
Commentary of "skin grafting the vascular pedicle: a useful technique to avoid microvascular collapse in free tissue transfer for limb salvage"
}

\author{
Francesco M. Egro, Eva Roy, Mario G. Solari \\ Department of Plastic Surgery, University of Pittsburgh Medical Center, 3550 Terrace Street 6B Scaife Hall Pittsburgh, Pittsburgh, \\ PA 15261, USA.
}

Correspondence to: Dr. Francesco M. Egro, Department of Plastic Surgery, University of Pittsburgh Medical Center, 3550 Terrace Street 6B Scaife Hall Pittsburgh, Pittsburgh, PA 15261, USA. E-mail: francescoegro@gmail.com

How to cite this article: Egro FM, Roy E, Solari MG. Commentary of "skin grafting the vascular pedicle: a useful technique to avoid microvascular collapse in free tissue transfer for limb salvage". Plast Aesthet Res 2019;6:14. http://dx.doi.org/10.20517/2347-9264.2019.30

Received: 25 Jun 2019 Accepted: 10 Jul 2019 Published: 22 Jul 2019

Science Editor: Raúl González-García Copy Editor: Jia-Jia Meng Production Editor: Jing Yu

We commend the authors on an excellent paper comparing the outcomes of microvascular transfers that utilized a skin graft for closure over the pedicle to a tension-free primary closure ${ }^{[1]}$. The retrospective cohort study of 71 patients found no significant difference in the rate of post-operative complications between the two groups. The authors concluded that skin graft closure over free flaps and pedicles may be an alternative technique to prevent compression in extremity free tissue transfers.

Free flaps offer the flexibility of mobilizing vascularized tissue to cover complex traumatic defects. It is important to emphasize the key principle in microsurgical reconstruction of traumatic limbs is performing the microvascular anastomosis well outside the zone of injury ${ }^{[2]}$. This should be done to prevent free flap failure typically due to arterial thrombosis or inadequate venous outflow ${ }^{[3]}$.

We agree that unfortunately the inability of obtaining primary closure may occur in microsurgical reconstruction of limbs and we commend the authors for providing evidence for a potential alternative. The inability to obtain primary closure occurs when local tissue inflammation and trauma leads to an increase in edema ${ }^{[4]}$, which in turn makes primary closure a challenge. In our experience, the inability to obtain primary closure is predominantly associated with free flaps to cover upper extremity defects due to the lack of mobility of tissues (especially around the wrist) ${ }^{[5]}$. It would have been interesting to see if an anatomical dominance existed in the study and if the complication rates differed based on them. 
It was interesting that conditions such as malnourishment and renal disease predispose patients to a significantly higher incidence of skin grafting use. In malnourishment, a lack of proteins may lead to a decrease in colloid osmotic pressure which in turn leads to diffusion of fluid in the interstitium, thus increasing edema ${ }^{[6]}$. Similarly in renal disease, there is urinary protein loss leading to decrease of plasma albumin and subsequently lowering the plasma oncotic pressure leading to an imbalance of the Starling forces $^{[7]}$. This drives fluid from the intravascular space to the interstitial space leading to fluid imbalance and potential for fluid overload. Both of these conditions contribute to the difficulty in primary closure and consequently skin grafting.

Skin grafting can be a significant issue when placed over a vascular pedicle. The thin and non-vascularized nature of the graft places the pedicle at risk for dessication and injury. Skin grafting has a greater propensity to contract at the recipient site due to the reduced volume of included dermis ${ }^{[8]}$. This can lead to compression of the pedicle secondary to scarring and graft contracture especially when localized around a joint. Furthermore, the skin graft donor site carries additional morbidities such as scarring, infection and pain $^{[9]}$, though as the authors mentions, redundant skin from the flap donor site is usually available without increasing scar length.

The concept of using skin grafting to cover free flap pedicles should be considered a last resort when everything else fails because of a concern of vascular injury and flap compromise. Although this study concludes that it is safe to adopt this technique, the small sample size and underpower of the study may make the authors conclusion premature.

The indication to employ a free flap in the first place is to obtain durable coverage of exposed critical structures such as tendon, bone, hardware, and vessels. We include the flap pedicle in this category. We suggest several methods to avoid skin grafting. One strategy is to make the free flap large enough to cover the entire course of the pedicle. This technique is simple, but may have a poorer cosmetic outcome due to the larger surface area of flap skin. Another strategy is to create an adipofascial extension to the free flap or create a chimeric flap. The anterolateral thigh (ALT) flap is particularly amenable to this. If an ALT does not require primary thinning, an extension of vascularized fascia plus adipose tissue can be draped over the pedicle. If the anastomosis site is too far from the defect, a chimeric flap can be designed, either adipofascial tissue on its own perforator, or a small segment of vastus or rectus muscle based on a branch close to the pedicle origin. Yet another method consists of rearranging tissues adjacent to pedicle ${ }^{[10,11]}$. Rearrangement strategies can be as simple as undermining and advancing local tissue or creating local flaps. When the incision to dissect recipient vessels is parallel to the defect, the skin bridge can be completely undermined and advanced as a bipedicle flap. If a local flap cannot be designed with primary closure of the donor site, we would prefer to have vascularized skin over the pedicle with a skin graft on the local flap donor site.

Designing a free flap that anticipates the steps required to obtain tension free closure over the pedicle can be challenging. Local tissue trauma or edema can compromise local flap options. If skin grafting is truly the only option, as situation we have also found ourselves in, we recommend harvesting the skin graft from the free flap donor site as described by the authors to avoid additional scarring. If this option is not available, a skin graft can be taken directly off the free flap ${ }^{[12]}$ to avoid the morbidity of a second donor $\operatorname{site}^{[13]}$. At our institution, we do not have a preference between full thickness and split-thickness skin grafts $^{[1,15]}$. The established benefits and drawbacks of take, contracture, tissue thickness, and esthetics are weighed by the surgeon.

We are grateful to Kovar et al. ${ }^{[1]}$ for shining insight on a very interesting topic and offering data on the use of skin grafting of the vascular pedicle. We do believe skin grafting should be used only as a last resort. 
However, it appears that skin grafting may be a suitable alternative for extremity free tissue transfers but further studies are warranted to confirm its safety and utility.

\section{DECLARATIONS}

\section{Authors' contributions}

Egro FM, Roy E, Soalri MG equally contributed to the ideation and writing of this commentary.

\section{Availability of data and materials}

Not applicable.

\section{Financial support and sponsorship}

Not applicable.

\section{Conflicts of interest}

All authors declared that there are no conflicts of interest.

\section{Ethical approval and consent to participate}

Not applicable.

\section{Consent for publication}

Not applicable.

\section{Copyright}

(c) The Author(s) 2019.

\section{REFERENCES}

1. Kovar A, Diamond S, Iorio ML. Skin grafting the vascular pedicle: a useful technique to avoid microvascular collapse in free tissue transfer to limb salvage. Plast Aesthtet Res 2019;6:10.

2. King EA, Ozer K. Free skin flap coverage of the upper extremity. Hand Clin 2014;30:201-9.

3. Wong AK, Joanna Nguyen T, Peric M, Shahabi A, Vidar EN, et al. Analysis of risk factors associated with microvascular free flap failure using a multi-institutional database. Microsurgery 2015;35:6-12.

4. Scallan J, Huxley VH, Korthuis RJ. Pathophysiology of Edema Formation. In: Capillary Fluid Exchange: Regulation, Functions, and Pathology. San Rafael (CA): Morgan \& Claypool Life Sciences; 2010.

5. Ng ZY, Salgado CJ, Moran SL, Chim H. Soft tissue coverage of the mangled upper extremity. Semin Plast Surg 2015;29:48-54.

6. Coulthard MG. Oedema in kwashiorkor is caused by hypoalbuminaemia. Paediatr Int Child Health 2015;35:83-9.

7. Bobkova I, Chebotareva N, Kozlovskaya L, Shilov E. Edema in Renal Diseases-Current View on Pathogenesis. Nephrol @ Point Care 2016;2: doi: 10.5301/pocj.5000204.

8. Greenwood JE. The evolution of acute burn care - retiring the split skin graft. Ann R Coll Surg Eng1 2017;99:432-8.

9. Shimizu R, Kishi K. Skin graft. Plast Surg Int 2012;2012:563493.

10. Fleming ME, O'Daniel A, Bharmal H, Valerio I. Application of the orthoplastic reconstructive ladder to preserve lower extremity amputation length. Ann Plast Surg 2014;73:183-9.

11. Gonzalez-Garcia R, Ruiz-Laza L, Manzano D, Monje F. Combined local triangular full-thickness skin graft for the closure of the radial forearm free flap donor site: a new technique. Plast Reconstr Surg 2010;125:85e-6e.

12. Ghanem TA, Wax MK. A novel split-thickness skin graft donor site: the radial skin paddle. Otolaryngol Head Neck Surg 2009;141:390-4.

13. Kim PD, Fleck T, Heffelfinger R, Blackwell KE. Avoiding secondary skin graft donor site morbidity in the fibula free flap harvest. Arch Otolaryngol Head Neck Surg 2008;134:1324-7.

14. Davis WJ 3rd, Wu C, Sieber D, Vandevender DK. A comparison of full and split thickness skin grafts in radial forearm donor sites. J Hand Microsurg 2011;3:18-24.

15. Prasetyono TO, Sadikin PM, Saputra DK. The use of split-thickness versus full-thickness skin graft to resurface volar aspect of pediatric burned hands: A systematic review. Burns 2015;41:890-906. 